\title{
EN MEMORIA DE RAIMUNDO LIDA
}

\author{
POR \\ ANA MARIA BARRENECHEA \\ Columbia University
}

E1 20 de junio de 1979 la comunidad de las letras hispánicas perdió un maestro y uno de los hombres espiritualmente más ricos y nobles. La palabra maestro se ha desgastado y trivializado. Aplicada a Raimundo Lida adquiere su dimensión justa. Pocos como él supieron acercarse a sus discípulos con una actitud que descubría lo mejor de cada uno y lo llevaba a su plena realización. Pocos como él entregaron su tiempo, su saber, sin restricciones. Pocos como él supieron ofrecer en la cátedra, en el seminario, en la discusión personal, en la obra escrita, lo que era al mismo tiempo un modo paradigmático de trabajar, de pensar, de crear, de actuar. Raimundo Lida se asustaría y se rebelaría si leyera que le atribuyo esa condición paradigmática, pero la tuvo, paradójicamente - sin quererlo, con modestia, con pudor, con respeto a la libertad del interlocutor-, y aún se ofrece perdurable a través de su obra escrita.

Raimundo Lida nació en Lemberg (Alemania), y al trasladarse muy pronto su familia a la Argentina, se crió y se educó en Buenos Aires. Era escasamente porteño en sus rasgos exteriores, en su modo de hablar, de vestirse o de moverse, pero sí lo era en sus recuerdos entrañables, en la persistente memoria de nombres de calles, de plazas, hasta de las madreselvas de lás tapias en el camino cotidianamente recorrido.

En tres países desarrolló su labor de investigador y formador de investigadores, y una tarea cultural que partiendo de la cátedra se ampliaba en círculos cada vez más vastos. En la Argentina, especialmente en Buenos Aires, pasó casi la mitad de su vida (en el Instituto Nacional Superior del Profesorado, donde enseñó; en el Instituto de Filología de la Facultad de Filosofía y Letras, donde fue discípulo y después amigo y colaborador de Amado Alonso, junto con Pedro Henríquez Ureña; en los cursillos de El Colegio Libre de Estudios Superiores; en Sur, que dirigió fugazmente, y en otras múltiples revistas y empeños editoriales), 
pero también actuó en la ciudad de La Plata, en cuya Facultad de Humanidades dictó estética por breve tiempo, y donde anudó su amistad con Alejandro Korn.

En 1947 pasó a México, a prolongar la Revista de Filología Hispánica de Buenos Aires con su continuadora, la actual Nueva Revista de Filología Hispánica, y a dar vida al Centro de Estudios Linguísticos y Literarios de El Colegio de México en 1948. Por último se trasladó, en 1953, a la Universidad de Harvard como profesor de español y llegó a ocupar la famosa cátedra Smith, antes asignada a Longfellow, Ticknor y Amado Alonso.

Conocí a Raimundo Lida en Buenos Aires hacia 1933, cuando estudiaba yo en el Instituto Nacional Superior del Profesorado. Al pedir licencia uno de sus profesores, se habló de que vendría a sustituirlo un joven de saber casi «mítico» que trabajaba en el ya famoso Instituto de Filología. A pesar de tener aprobada la materia, asistí el primer día a su clase, un poco por curiosidad: el primer día... y todos los siguientes, sin perder uno, porque lo que oíamos era una lectura nueva y fascinante de esos textos que creíamos tan sabidos.

Para entonces había publicado en Sur, en 1931, «Estilística. Un estudio sobre Quevedo». Este artículo (que aún sigue siendo trabajo de consulta indispensable en la bibliografía de Quevedo) adelantaba ya alguno de los caminos que seguiría magistralmente más adelante y también varios rasgos permanentes de su carácter. Al comentar la obra de Leo Spitzer Sobre el arte de Quevedo en su 'Buscón', presentaba una corriente crítica que entonces se ofrecía como uno de los métodos más ricos del análisis literario; no negaba al colega el generoso reconocimiento, pero apuntaba cordialmente sus disidencias y proponía a su vez enfoques personales. Así contribuía a la tarea común de revalorar a nuestros clásicos, con la comprensión aguda, matizada, compleja y lúcida que siempre lo distinguió, y que irá ahondándose a través de los años.

En aquella época de Buenos Aires, Raimundo Lida se dedicaba, como la mayoría de los colaboradores del Instituto de Filología, a los trabajos linguiísticos y literarios, pero agregaba una vena particular suya: el interés por la filosofía del lenguaje y los problemas de estética. En 1933 empezaron a aparecer sus artículos sobre estas disciplinas, que se continuarían hasta su viaje a México: trabajos sobre Bergson, Husserl, Heidegger, Croce, Gentile, Locke, Berkeley, Hume, Herder, Spengler, y reseñas como la del Fermentario de Vaz Ferreira o The New Criticism de Ramson, cuando nadie hablaba de ese movimiento crítico fuera de los Estados Unidos. Su tarea culminó en un libro ejemplar: Belleza, arte y poesía en la estética de Santayana (1943), obra clave en la bibliografía 
general de Santayana y sin duda el libro de estética más importante que ha producido el mundo hispánico en su generación. Esta vena tan suya es la que, aun abandonada más tarde como temática, siguió dando a sus trabajos literarios la densidad que los distingue en la crítica contemporánea.

Mientras tanto, colaboraba con Amado Alonso en el Instituto de Filología en las dos colecciones de Dialectología Hispanoamericana y de Estudios Estilísticos, y en la Revista de Filología Hispánica. Quiero sólo citar como un ejemplo el tomo dedicado a El impresionismo en el lenguaje, donde se unen la elección acertada de artículos sobre el tema, la traducción cuidadosa y adecuada a la nueva lengua con ejemplos hispánicos homólogos y la labor bibliográfica. El trabajo culmina con un estudio de Amado Alonso y Raimundo Lida escrito en colaboración: «El concepto linguístico de impresionismo», que replantea el problema en forma certera e iluminadora.

¿Qué sabíamos de Raimundo Lida los que tuvimos el privilegio de compartir con él las tareas diarias del Instituto? ¿Qué recibíamos de él, junto con el don inapreciable de su amistad? Sabíamos que era un placer recoger una frase suya intercalada al pasar, leer unas páginas que revelaban su infalible gusto personal y sus sutiles asociaciones (las que nos conmovían como si las hubiésemos descubierto nosotros sabiendo que nunca se nos habría dado ese hallazgo). Sabíamos que encontraríamos en el escritorio una ficha de su letra menuda sobre algún tema que investigábamos, y, más adelante, el diálogo, el humor nunca destructor, la frase que oponía discretamente un leve «pero» a lo que habíamos afirmado, el silencio que podía oírse mejor a veces que la palabra, o la alusión que abría posibilidades al que tenía el oído atento.

Cuando el Instituto de Filología se dispersó por circunstancias que todos conocemos y encontró acogida generosa en El Colegio de México, fundado por Alfonso Reyes, surgió naturalmente el nombre de Raimundo Lida como único candidato posible para dirigir el nuevo centro de investigaciones filológicas. No lo perdimos del todo. Continuamos el diálogo y las enseñanzas por carta. Era el amigo y también el maestro indiscutible, casi de nuestra misma edad, al que por eso se recurría con mayor confianza a pesar de la distancia. A él acudíamos para pedir consejo y orientación o en busca del juicio definitivo. Y el manuscrito volvía lleno de anotaciones, ponderando lo acertado, exigiendo mayor precisión en el perfil de algunos pasajes que habíamos dejado torpemente esbozados, sin duda porque no habíamos sabido aclarárnoslo a nosotros mismos. Así nos obligaba a repensar lo dicho hasta hallar la fórmula ajustada. Años más tarde, al encontrarme con sus discípulos y colegas 
de E1 Colegio de México o de Harvard, todos conservaban ese recuerdo del maestro que da ejemplo vivo en sus clases y en su propia obra, y continúa ofreciendo su tiempo con generosidad sin tasa en el comentario de los trabajos ajenos.

En El Colegio de México atrajo y formó un grupo de colaboradores notables, creó una rigurosa tradición de investigadores de la literatura, de la que es ejemplo la Nueva Revista de Filología Hispánica, la obra personal y la que suscitó en los demás. En 1958 recogió parte de sus páginas dispersas en Letras hispánicas, volumen que en la variedad de tonos y temas representa cabalmente las constantes de su espíritu. La línea de sus intereses sobre estética, poética, filosofía del lenguaje se desenvuelve desde «Condición del poeta», o la breve pero compleja elaboración de "Kierkegaard y la poética actual», "Recuerdo de Korn», «Santayana», hasta la extensa monografía «Bergson, filósofo del lenguaje» (y echamos de menos los que no quiso incluir sobre teoría del lenguaje, pero que, para decirlo con sus palabras, «siguen gravitando sobre él [volumen] desde el destierro»). A su lado se desarrollan los grandes temas de literatura española e hispanoamericana, entre los que se destacan ya en esta época Quevedo y Darío.

Los trabajos pueden tomar la forma de ensayos «casi alados», como "Condición del poeta», donde no se sabe qué admirar más, si la contenida pasión por el tema, la simultánea capacidad de amplitud y síntesis o la sabia red de alusiones. Porque podemos partir de Platón, Plutarco o Cicerón y seguir andando por los senderos de San Agustín, Tertuliano o el propio Alfonso el Sabio (con curiosos pasajes laterales que desembocan en el Quijote, en Goethe o en el mundo islámico, que a su vez nos llevan a Keats o Kierkegaard...), para concluir en Ibsen o en nuestro Almafuerte. Todo ello sin perder las líneas generales del pensamiento, con alusiones iluminadoras que nunca son mero ornato y que muestran un conocer auténtico, un largo comercio con lo que apenas se roza en el texto.

Otros artículos dedicados a un solo autor se desenvuelven con la misma condensación que lo caracterizaba. Sólo citaré dos ejemplos: los de Borges y Korn. "Notas a Borges» revela en apretada síntesis, que vale por todo un libro (y que regala ideas para varios libros), lo paradóicico y lo esencial de este elusivo escritor. «Recuerdo de Korn» es el relato del descubrimiento progresivo de una personalidad compleja, en encuentros fragmentarios directos y en sus textos. Hoy la literatura creadora y la crítica nos están acostumbrando a percibir, más que los artefactos conclusos y estáticos, los procesos en su dinámica y en su apertura. Por eso ahora nos sorprende la relectura de este ensayo, que es además un 
diálogo-relectura de Raimundo Lida con los recuerdos y los textos del maestro y un testimonio de las transformaciones de esta experiencia personal.

Junto a los ensayos y las notas se destacan tres bloques monográficos: los artículos sobre Quevedo, «Los cuentos de Darío» y «Bergson, filósofo del lenguaje». El estudio de Darío constituye un modelo de metodología y un ejemplo aún no superado de interpretación particular de la prosa del poeta, que servirá siempre de base a la caracterización general de la prosa modernista y a un capítulo de la renovación de la prosa en lengua española. En su trabajo de Bergson, el afán de perfección lo fue llevando desde 1933 a cambiar la redacción de un párrafo, a agregar un dato, a sustituir una cita, a ampliar o precisar un concepto. En tal sentido es ejemplar la reelaboración a la que lo sometió, acumulada durante dos décadas en múltiples papeletas, extraviadas por un azar y luego reconstruidas pacientemente. Así nos dejó una obra imprescindible en la extensa bibliografía bergsoniana sobre la concepción de la intuición poética y su conformación por el lenguaje.

En Harvard, Raimundo Lida continuó su labor, ya totalmente centrada en la crítica literaria de autores específicos. A los artículos de Quevedo reunidos en México siguieron otros en los que fija el rebelde perfil de una obra torturada, en el esplendor de sus hallazgos imaginativos verbales, con sus luces y sus sombras (ásperas sombras a veces), que destaca en constante conexión con la política y la cultura de su época. Poco antes de morir continuaba completando el libro que le dedicó y que sólo su increíble anhelo de perfección retenía entre las manos. Nos había dado paralelamente otros trabajos, entre los que quiero recordar las páginas de lírica moderna (Salinas, Guillén, Darío, García Lorca) y aquéllas llenas de sugerencias sobre Cervantes, el autor más afín a su hondura humana.

Esas dos vías se abrían a su afán incansable de inquisición poética cuando lo sorprendió la muerte. Quisiera proponer a los jóvenes estudiosos del mundo hispánico, y sobre todo a los argentinos, tan desvalidos y menesterosos de pautas culturales, la relectura de su obra, donde con una frase suya que podría definirlo a él mismo: «Todo se nos comunica con el mayor orden y lucidez, pero no con esa perfección de lo "definitivo', de lo fríamente cerrado en sí, que arredra y descorazona. Es un saber cabal y luminoso y, al mismo tiempo, un saber vuelto hacia el futuro.» 
